\title{
Coagulation Assay and Stroke Severity upon Admission of Patients with Cardioembolic Cerebral Infarction during Direct Oral Anticoagulant Use
}

\author{
Ichiro Deguchi, ${ }^{1}$ Takashi Osada, ${ }^{1}$ Masaki Takao ${ }^{1,2}$ and Shinichi Takahashi ${ }^{1}$ \\ ${ }^{1}$ Department of Neurology and Cerebrovascular Medicine, Saitama Medical University International Medical \\ Center, Hidaka, Japan \\ ${ }^{2}$ Department of Clinical Laboratory, National Center of Neurology and Psychiatry Hospital, Tokyo, Japan
}

(Received for publication on December 22, 2020)
(Revised for publication on February 4, 2021)
(Accepted for publication on February 15, 2021)
(Published online in advance on March 16, 2021)

\begin{abstract}
Although the severity of acute cerebral infarction varies in patients receiving direct oral anticoagulants (DOACs), no practical method to predict the severity has been established. We analyzed retrospectively the relationship between cardioembolic cerebral infarction severity and coagulation indicators in patients treated with DOACs. We assessed the anticoagulation effect of DOACs using the activated partial thromboplastin time (APTT), prothrombin time (PT), and prothrombin time international standardized ratio (PT-INR) in 71 patients with cardioembolic cerebral infarction admitted to our hospital between January 2015 and December 2019. The participants were divided into a prolongation group (prolonged APTT for oral thrombin inhibitors or prolonged PT for oral factor Xa inhibitors, $\mathbf{n}=37$ ) and a normal group (no prolongation of coagulation markers, $n=34)$. Of the 71 patients, $21(30 \%)$ and $50(\mathbf{7 0} \%)$ were using oral thrombin and oral factor Xa inhibitors, respectively. PT, PT-INR, and APTT were significantly higher in the prolongation group (PT: $17.4 \pm 5.1$ vs. $12.8 \pm 1.4 \mathrm{~s}, P<0.001$; PT-INR: $1.5 \pm 0.5$ vs. $1.1 \pm 0.1, P<0.001 ;$ APTT: $44.8 \pm 26.4$ vs. $30.4 \pm 4.1 \mathrm{~s}, P=0.003)$. The median National Institutes of Health Stroke Scale (NIHSS) score on admission and the prevalence of large vessel occlusion were significantly lower in the prolongation group (NIHSS: 2.0 vs. 9.5, $P=0.007$; large vessel occlusion: $27 \%$ vs. $53 \%, P=0.031$ ). The prevalence of large vessel occlusion was low and stroke severity was mild in patients undergoing DOAC therapy with prolongation of coagulation assay markers upon onset of cardioembolic cerebral infarction. (DOI: 10.2302/ kjm.2020-0019-OA)
\end{abstract}

Keywords: direct oral anticoagulant, cardioembolic stroke, coagulation assays, stroke severity, large vessel occlusion

\section{Introduction}

In Japan, warfarin (a vitamin $\mathrm{K}$ antagonist) was used for many years as the only oral anticoagulant for the prevention of embolism in patients with atrial fibrillation. However, four direct oral anticoagulants (DOACs) have become clinically available since 2011 , i.e., the oral thrombin inhibitor dabigatran and three oral factor Xa in- hibitors (rivaroxaban, apixaban, and edoxaban). A metaanalysis of randomized controlled trials has revealed that these DOACs possess comparable or higher efficacy and safety compared with well-controlled warfarin. ${ }^{1}$

Importantly, however, a substantial number of cerebral infarctions recur despite treatment with oral anticoagulants. ${ }^{2}$ Moreover, several reports have indicated that the severity of cerebral infarction is milder in patients receiv-

Reprint requests to: Ichiro Deguchi, MD, PhD, Department of Neurology, Saitama Medical University International Medical Center, 1397-1 Yamane, Hidaka, Saitama 350-1298, Japan, E-mail: ideguchi@saitama-med.ac.jp

Copyright (C) 2021 by The Keio Journal of Medicine 
ing DOACs than in those not receiving anticoagulants or in those with a blood warfarin concentration below the optimal range. ${ }^{3-5}$ Furthermore, it has been reported that the proportion of patients with large vessel occlusion (LVO) at the onset of cerebral infarction is lower in patients receiving DOACs. ${ }^{6}$ Moreover, low DOAC plasma levels are reportedly associated with LVO and higher stroke severity on admission to hospital. ${ }^{7}$ However, the measurement of plasma DOAC levels is difficult by routine testing in clinical practice. In the current study, we retrospectively examined how the activated partial thromboplastin time (APTT) and prothrombin time (PT), which are widely used in coagulation assays to assess the anticoagulant effect of DOACs in clinical practice, were associated with the severity of cardiogenic embolism on admission in patients being treated with these drugs.

\section{Materials and Methods}

Of the 443 consecutive patients with acute cardioembolic cerebral infarction resulting from non-valvular fibrillation who were admitted to our hospital between January 1, 2015, and December 31, 2019, 71 were being treated with DOAC therapy and were included in the study. These patients were divided into groups, those with and those without prolonged clotting times, and were retrospectively compared.

All 71 patients were prescribed DOACs for non-valvular atrial fibrillation (NVAF). Patients who were not independent in activities of daily living and those with diseases affecting coagulation (e.g., hepatic disorders, autoimmune diseases, and malignant tumors) were excluded from the study.

All patients had concomitant NVAF that was confirmed from the data available in their medical records based on electrocardiography (ECG), bedside ECG monitoring, 24-h Holter monitoring, and echocardiography. Comparisons were made between the normal and the prolongation groups with respect to age, sex, body weight, risk factors for cerebral infarction (hypertension, diabetes mellitus, heart failure), history of previous ischemic stroke, coronary artery disease, type of atrial fibrillation, laboratory test results on admission (creatinine levels [Cr], creatinine clearance $\left[\mathrm{C}_{\mathrm{Cr}}\right.$, calculated using the Cockcroft-Gault equation $^{8}$ ] PT, PT-international normalized ratio [INR], APTT, D-dimer levels), National Institutes of Health Stroke Scale (NIHSS) score ${ }^{9}$ on admission, $\mathrm{CHADS}_{2}$ and $\mathrm{CHA}_{2} \mathrm{DS}_{2}$-Vasc scores ${ }^{10,11}$ (atrial fibrillation stroke risk measures) before stroke onset, the time between stroke onset and blood sampling, the time between stroke onset and magnetic resonance angiography (MRA), the prevalence of LVO, and the percentage of patients treated with off-label doses of DOAC (i.e., usage not in accordance with the medical package insert). Medical records (data from the patients and their families, prescriptions, and referral forms, among others) were used for analysis and comparison. Prolongation of the coagulation time was defined as a coagulation assay indicator exceeding the criterion ranges (APTT, 24-39 s; PT, 11-13 s; PT-INR, 0.9-1.1); APTT was used in patients treated with an oral thrombin inhibitor and PT was used in patients treated with oral factor Xa inhibitors. At our hospital, PT and APTT were measured using a Coagpia PT-N kit and a Coagpia APTT-N kit (Sekisui Medical, Tokyo, Japan), respectively. The diagnosis of cardiogenic cerebral infarction was made in accordance with the criteria given in the ORG 10172 in acute stroke treatment (TOAST) trial. ${ }^{12}$ The diagnosis of cerebral infarction and occluded vessels was based on the findings from diffusion-weighted magnetic resonance imaging (MRI) and MRA on admission, with the large vessels defined as the internal carotid artery, the middle cerebral artery (M1 segment, M2 proximal segment), and the basilar artery.

This retrospective study was approved by the Human Research Ethics Committee of Saitama Medical University International Medical Center (No. 20-026) and was carried out by employing the opt-out method using our hospital website.

\section{Statistical analysis}

Data were analyzed using the SPSS package (version 20; IBM, Armonk, NY, USA). Age, body weight, $\mathrm{Cr}, \mathrm{C}_{\mathrm{Cr}}$, PT, PT-INR, APTT, the time between stroke onset and blood sampling, the time between stroke onset and MRA, and $\mathrm{D}$-dimer levels were compared between groups using Student's t-test. The $\mathrm{CHADS}_{2} / \mathrm{CHA}_{2} \mathrm{DS}_{2}$-Vasc scores and the NIHSS score were compared using the Mann-Whitney U test, and ratios were compared using Fisher's exact test (two-sided). Furthermore, regarding the presence/absence of large cerebral artery obstruction, the area under the curve (AUC), sensitivity, specificity, and cut-off level were calculated from the receiver operating characteristic (ROC) curve.

\section{Results}

The background variables for the prolongation group and the normal group are shown in Table 1. Of the 71 patients, $21(30 \%)$ were using an oral thrombin inhibitor and $50(70 \%)$ were using oral factor Xa inhibitors (Fig. 1). Thirty-seven patients (52\%) were allocated to the prolongation group and $34(48 \%)$ to the normal group. PT was significantly higher in the prolongation group than in the normal group (mean $\pm \mathrm{SD}, 17.4 \pm 5.1 \mathrm{~s}$ vs. $12.8 \pm 1.4$ $\mathrm{s}, P<0.001)$. PT-INR was also significantly higher in the prolongation group than in the normal group $(1.5 \pm 0.5$ vs. $1.1 \pm 0.1, P<0.001)$, as was APTT $(44.8 \pm 26.4 \mathrm{~s}$ vs. $30.4 \pm 4.1 \mathrm{~s}, P=0.003)$. D-dimer levels were higher in the normal group than in the prolongation group, although not significantly so. The median NIHSS score on admis- 
Table 1. Clinical characteristics of the prolongation group and the normal group for all patients

\begin{tabular}{|c|c|c|c|}
\hline Variable & Prolongation group $(n=37)$ & Normal group $(n=34)$ & $P$ value \\
\hline Age, years & $76.2 \pm 6.4$ & $75.5 \pm 7.7$ & 0.691 \\
\hline Female & $14(38)$ & $7(21)$ & 0.127 \\
\hline Hypertension & $25(68)$ & $24(71)$ & 0.803 \\
\hline Heart failure & $9(24)$ & $6(18)$ & 0.569 \\
\hline Diabetes mellitus & $9(24)$ & $7(21)$ & 0.781 \\
\hline Previous coronary heart disease & $5(14)$ & $4(12)$ & 1.000 \\
\hline Previous cerebral infarction & $15(41)$ & $13(38)$ & 1.000 \\
\hline Body weight, $\mathrm{kg}$ & $59.18 \pm 10.26$ & $57.83 \pm 10.95$ & 0.593 \\
\hline Creatinine, $\mathrm{mg} / \mathrm{dL}$ & $0.857 \pm 0.28$ & $0.79 \pm 0.18$ & 0.263 \\
\hline Creatinine clearance, $\mathrm{mL} / \mathrm{min}$ & $62.54 \pm 20.14$ & $66.33 \pm 19.29$ & 0.421 \\
\hline $\mathrm{CHADS}_{2}$ score & $3(2-3)$ & $3(2-3)$ & 0.612 \\
\hline $\mathrm{CHA}_{2} \mathrm{DS}_{2}$-Vasc score & $4(3-5)$ & $4(2.25-5)$ & 0.183 \\
\hline NIHSS score & $2(1-10)$ & $9.5(2-19.5)$ & 0.007 \\
\hline Onset to blood sampling, min & $447.7 \pm 547.4$ & $506.3 \pm 786.4$ & 0.715 \\
\hline Onset to MRA, min & $494.2 \pm 546.8$ & $538.9 \pm 805.5$ & 0.784 \\
\hline PT, s & $17.38 \pm 5.12$ & $12.75 \pm 1.43$ & $<0.001$ \\
\hline PT-INR & $1.47 \pm 0.46$ & $1.07 \pm 0.13$ & $<0.001$ \\
\hline APTT, s & $44.74 \pm 26.38$ & $30.39 \pm 4.06$ & 0.003 \\
\hline $\mathrm{D}$-dimer, $\mu \mathrm{g} / \mathrm{mL}$ & $1.30 \pm 1.31$ & $1.92 \pm 2.03$ & 0.126 \\
\hline DOAC & & & 0.193 \\
\hline Thrombin inhibitor & $8(22)$ & $13(38)$ & \\
\hline Factor $\mathrm{Xa}$ inhibitors & $29(78)$ & $21(62)$ & \\
\hline Off-label dose & $10(27)$ & $7(21)$ & 0.586 \\
\hline $\mathrm{PaF}$ & $2(5)$ & 0 & 0.494 \\
\hline Large vessel occlusion & $10(27)$ & $18(53)$ & 0.031 \\
\hline ICA & 2 & 7 & \\
\hline MCA M1 & 6 & 8 & \\
\hline MCA M2 & 1 & 2 & \\
\hline BA & 1 & 1 & \\
\hline
\end{tabular}

Data are shown as mean $\pm \mathrm{SD}$, median (interquartile range), or number (\%).

$\mathrm{BA}$, basilar artery; $\mathrm{CHADS}_{2}$, score based on congestive heart failure, hypertension, age $\geq 75$ years, diabetes mellitus, and prior stroke/transient ischemic attack; $\mathrm{CHA}_{2} \mathrm{DS}_{2}$-Vasc, score based on congestive heart failure/left ventricular dysfunction, hypertension, age of 75 years or older or 65-74 years, diabetes mellitus, stroke/transient ischemic attack, vascular disease and female sex; ICA, internal carotid artery; MCA, middle cerebral artery; PaF, paroxysmal atrial fibrillation.

sion was significantly higher in the normal group than in the prolongation group ( 9.5 vs. $2.0, P=0.007$ ). The prevalence of LVO was significantly higher in the normal group than in the prolongation group (53\% vs. $27 \%, P=$ $0.031)$.

We analyzed the differences associated with the action of DOAC mechanisms. The background variables of patients classified by the drug used before disease onset (an oral thrombin inhibitor or oral factor Xa inhibitors) are shown in Tables 2 and 3, respectively. Among the patients using an oral thrombin inhibitor, there remained a significant between-group difference for coagulation markers, and the NIHSS score on admission and the prevalence of LVO were higher in the normal group than in the prolongation group, although not significantly so (Table 2). On the other hand, among patients using oral factor Xa inhibitors, the median NIHSS score on admission was significantly higher in the normal group than in the prolongation group (12 vs. 2, $P=0.015$ ) (Table 3). The prevalence of LVO was also significantly higher in the normal group than in the prolongation group $(62 \%$ vs. $31 \%, P=0.044$ ) (Table 3). Furthermore, according to the results of the ROC analysis of LVO in relation to PT and PT-INR among patients using oral factor Xa inhibitors, the optimum cut-off level of PT was $14.55 \mathrm{~s}$ (AUC, 0.679; sensitivity, 0.571; specificity, 0.773) (Fig. 2A) and the optimum cut-off level of PT-INR was 1.08 (AUC, 0.700; sensitivity, 0.821; specificity, 0.545) (Fig. 2B). 


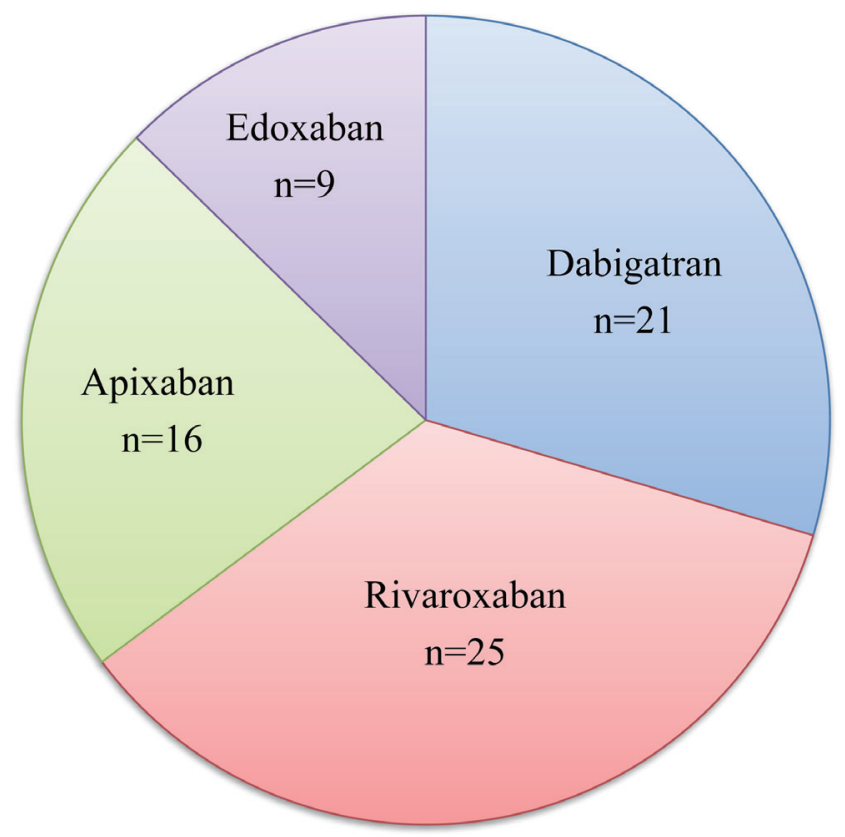

Fig. 1. Direct oral anticoagulants administered to patients. Of the 71 patients, $21(30 \%)$ received an oral thrombin inhibitor (dabigatran), and $50(70 \%)$ were treated with oral factor Xa inhibitors (edoxaban, apixaban, or rivaroxaban).

\section{Discussion}

In the present study, patients showing prolongation of anticoagulation activity on admission with cardiogenic cerebral embolism during oral DOAC therapy were less likely to have complications in the form of LVO. Consequently, such patients presented with lower stroke severity compared to those showing normal anticoagulation activity. When analyzed in light of the mechanism of action of DOACs, patients being treated with oral factor Xa inhibitors who were in the prolongation group also had a lower prevalence of complications in the form of LVO and presented with lower stroke severity compared with patients in the normal group.

DOACs exhibit anticoagulation activity over a wide range of blood drug levels and do not require frequent blood drug level monitoring for the purpose of dose level adjustment (as is needed for warfarin). Nevertheless, a coagulation test is useful in interpreting blood drug levels (i.e., the anticoagulant effect). The parameters used for such tests are: (1) the thrombin time (TT), the dilute TT, and APTT for oral thrombin inhibitors; and (2) antifactor Xa activity and PT for oral factor Xa inhibitors. ${ }^{13}$ For factor Xa inhibitors, PT-INR is normal or prolonged if the blood drug level is within the effective range, and PT-INR is normal if the blood drug level is lower than the effective range. In contrast, with thrombin inhibitors,
APTT is normal or prolonged if the blood drug level is within the effective range, although there are cases in which APTT is prolonged even when the blood drug level is lower than the effective range..$^{13}$ Among patients receiving oral thrombin inhibitors, no significant differences were observed in NIHSS scores or the proportion of patients with LVO between the prolongation group and the normal group. However, the small sample size presumably had a major impact, although the above-mentioned factors might have also affected this result.

In patients with prolonged coagulation assay indicators, the stroke severity on admission tended to be lower. Two mechanisms possibly explain this finding. First, the embolus may be small if the blood DOAC level is within (or higher than) the effective range. Second, even in cases where LVO develops, the artery may undergo spontaneous early recanalization as a result of the thrombolytic action of DOACs, leading to reduced severity of the condition upon admission. In a report suggesting the former mechanism, it was reported that if the DOAC's level of anticoagulant activity on admission is high, the incidence of LVO will be low, and that a low antithrombotic activity serves as an independent predictor of LVO onset. ${ }^{7}$ Regarding the latter mechanism, using their mouse model of embolic stroke in which the embolus was made ex vivo without being influenced by rivaroxaban, Katsumata et al. ${ }^{14}$ demonstrated that the recanalization rate was higher in a rivaroxaban-treated group than in a control group.

Limitations of the current study include (1) the retrospective study design, (2) the inability to check the presence/absence and timing of drug intake, (3) tests were performed using only those reagents normally used at our hospital, (4) the small sample size (we were unable to perform the desired statistical analyses, such as multivariate regression analysis), and (5) we evaluated all factor Xa inhibitors collectively. Our results suggest that, if cerebral infarction occurs during DOAC therapy, patients with prolonged PT or APTT might suffer a milder cerebral infarction. However, several reports have indicated that APTT and PT-INR derived from standard coagulation tests do not adequately reflect the anticoagulant activity of DOACs and that results are difficult to interpret. ${ }^{15-18}$ Alternatively, concentrations of DOAC can be reflected by using another simple method (point-of-care testing) as reported in the literature. ${ }^{19,20}$ Although the extent to which PT and APTT (obtained from tests with the reagents used in this study) reflect the blood concentrations of DOACs remains unknown, they appeared to be potential indicators able to predict the severity of cerebral infarction at the onset. Further studies with larger numbers of subjects as well as studies comparing different reagents and types of DOACs are necessary to investigate whether PT and APTT, which are easy to measure and were used in this study, are associated with the severity of stroke and the occlusion of large vessels. 
Table 2. Clinical characteristics of the prolongation group and the normal group of patients treated with an oral thrombin inhibitor

\begin{tabular}{|c|c|c|c|}
\hline Variable & Prolongation group $(n=8)$ & Normal group $(\mathrm{n}=13)$ & $P$ value \\
\hline Age, years & $75.5 \pm 5.6$ & $75.7 \pm 4.3$ & 0.986 \\
\hline Female & $5(63)$ & $2(15)$ & 0.056 \\
\hline Body weight, $\mathrm{kg}$ & $62.60 \pm 9.76$ & $62.73 \pm 10.80$ & 0.978 \\
\hline Creatinine, $\mathrm{mg} / \mathrm{dL}$ & $0.80 \pm 0.18$ & $0.82 \pm 0.21$ & 0.796 \\
\hline Creatinine clearance, $\mathrm{mL} / \mathrm{min}$ & $64.75 \pm 11.52$ & $70.63 \pm 22.09$ & 0.497 \\
\hline $\mathrm{CHADS}_{2}$ score & $2.5(1.75-3.5)$ & $2(0-3)$ & 0.266 \\
\hline $\mathrm{CHA}_{2} \mathrm{DS}_{2}$-Vasc score & $5(3-5.25)$ & $3(1-4)$ & 0.095 \\
\hline NIHSS score & $1(0-6)$ & $4(2-14)$ & 0.135 \\
\hline Onset to blood sampling, min & $456.9 \pm 373.4$ & $327.5 \pm 336.5$ & 0.422 \\
\hline Onset to MRA, min & $511.8 \pm 416.8$ & $373.0 \pm 338.0$ & 0.413 \\
\hline PT, s & $16.23 \pm 2.87$ & $13.79 \pm 1.72$ & 0.024 \\
\hline PT-INR & $1.37 \pm 0.24$ & $1.16 \pm 0.15$ & 0.024 \\
\hline APTT, s & $67.06 \pm 49.42$ & $32.15 \pm 3.68$ & 0.018 \\
\hline $\mathrm{D}$-dimer, $\mu \mathrm{g} / \mathrm{mL}$ & $0.81 \pm 0.20$ & $1.34 \pm 0.86$ & 0.104 \\
\hline Off-label dose & $2(25)$ & $1(8)$ & 0.531 \\
\hline Large vessel occlusion & $1(13)$ & $5(38)$ & 0.085 \\
\hline ICA & 0 & 2 & \\
\hline MCA M1 & 1 & 2 & \\
\hline MCA M2 & 0 & 1 & \\
\hline BA & 0 & 0 & \\
\hline
\end{tabular}

Data are shown as mean $\pm \mathrm{SD}$, median (interquartile range), or number $(\%)$.

Table 3. Clinical characteristics of the prolongation group and the normal group of patients treated with oral factor Xa inhibitors

\begin{tabular}{|c|c|c|c|}
\hline Variable & Prolongation group $(n=29)$ & Normal group $(\mathrm{n}=21)$ & $P$ value \\
\hline Age, years & $76.5 \pm 6.7$ & $75.3 \pm 9.3$ & 0.704 \\
\hline Female & $9(31)$ & $5(24)$ & 0.752 \\
\hline Body weight, $\mathrm{kg}$ & $58.23 \pm 10.36$ & $54.79 \pm 10.12$ & 0.247 \\
\hline Creatinine, $\mathrm{mg} / \mathrm{dL}$ & $0.87 \pm 0.31$ & $0.77 \pm 0.16$ & 0.178 \\
\hline Creatinine clearance, $\mathrm{mL} / \mathrm{min}$ & $61.93 \pm 22.06$ & $63.67 \pm 17.37$ & 0.765 \\
\hline $\mathrm{CHADS}_{2}$ score & $3(2-3)$ & $3(2-4)$ & 0.697 \\
\hline $\mathrm{CHA}_{2} \mathrm{DS}_{2}$-Vasc score & $4(3-5)$ & $4(3-5)$ & 0.809 \\
\hline NIHSS score & $2(1-10)$ & $12(2-20)$ & 0.015 \\
\hline Onset to blood sampling, min & $445.2 \pm 591.8$ & $617.0 \pm 958.5$ & 0.438 \\
\hline Onset to MRA, min & $489.4 \pm 583.8$ & $641.6 \pm 986.4$ & 0.498 \\
\hline PT, s & $17.70 \pm 5.58$ & $12.10 \pm 0.97$ & $<0.001$ \\
\hline PT-INR & $1.50 \pm 0.50$ & $1.02 \pm 0.08$ & $<0.001$ \\
\hline APTT, s & $38.58 \pm 10.10$ & $29.31 \pm 3.97$ & $<0.001$ \\
\hline $\mathrm{D}$-dimer, $\mu \mathrm{g} / \mathrm{mL}$ & $1.44 \pm 1.45$ & $2.28 \pm 2.45$ & 0.132 \\
\hline Off-label dose & $7(24)$ & $6(29)$ & 0.754 \\
\hline Large vessel occlusion & $9(31)$ & $13(62)$ & 0.044 \\
\hline ICA & 2 & 5 & \\
\hline MCA M1 & 5 & 6 & \\
\hline MCA M2 & 1 & 1 & \\
\hline $\mathrm{BA}$ & 1 & 1 & \\
\hline
\end{tabular}

Data are shown as mean $\pm \mathrm{SD}$, median (interquartile range), or number $(\%)$. 
A

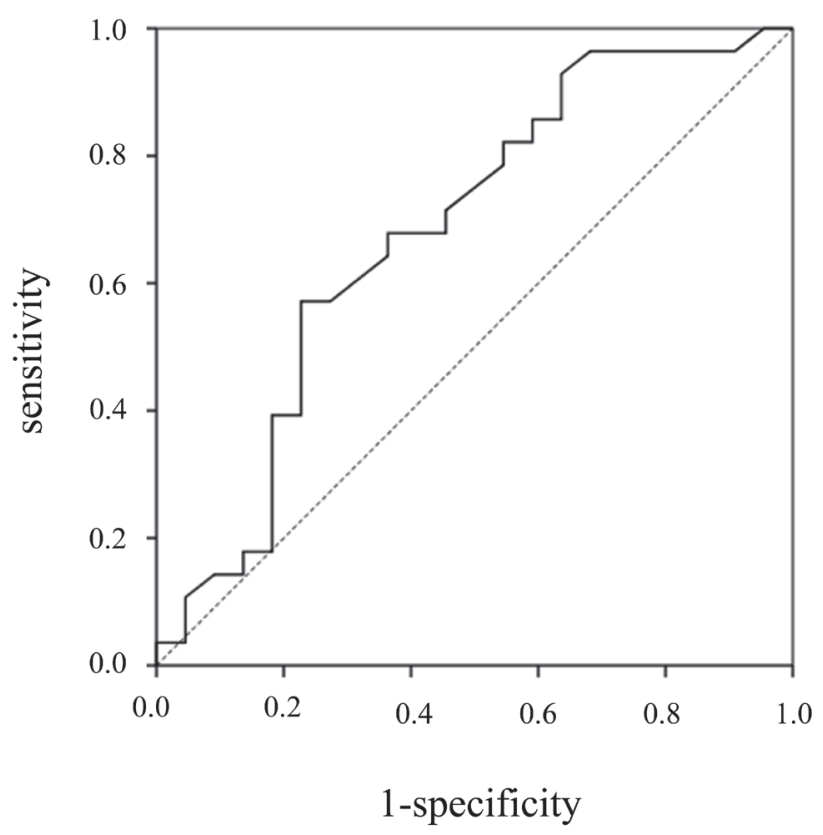

$\mathrm{B}$

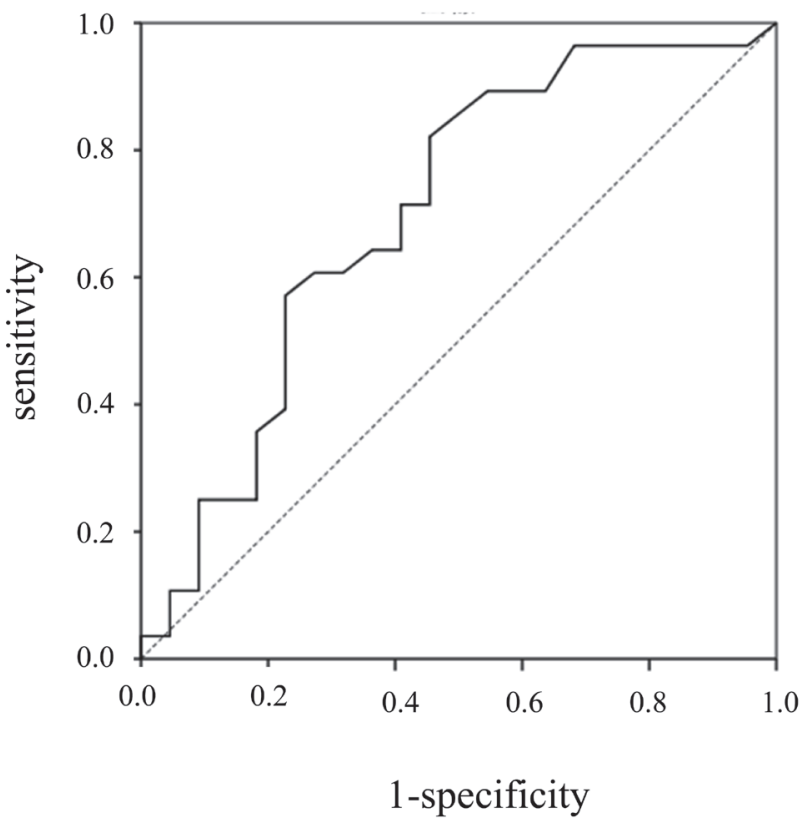

Fig. 2. Receiver operating characteristic curves for PT and PT-INR for large vessel occlusion among patients using oral factor Xa inhibitors.

(A) For PT, the area under the curve was 0.679, and the cut-off value was 14.55. (B) For PT-INR, the area under the curve was 0.700, and the cut-off value was 1.08 .

\section{Conclusions}

In patients who developed cardiogenic cerebral embolism during DOAC therapy, the prevalence of LVO may be lower and their condition on hospital admission may be less severe if there is an observed prolongation of APTT (for patients being treated with an oral thrombin inhibitor) or PT (for patients being treated with oral factor $\mathrm{Xa}$ inhibitors).

\section{Acknowledgments}

We thank Prof. Michio Shiibashi (Information Technology Center, Saitama Medical University) for his valuable comments regarding the statistical analysis.

\section{Conflicts of Interest}

The authors declare that no conflicts of interest exist.

\section{References}

1. Ruff CT, Giugliano RP, Braunwald E, Hoffman EB, Deenadayalu N, Ezekowitz MD, Camm AJ, Weitz JI, Lewis BS, Parkhomenko A, Yamashita T, Antman EM: Comparison of the efficacy and safety of new oral anticoagulants with warfarin in patients with atrial fibrillation: a meta-analysis of randomised trials. Lancet 2014; 383: 955-962. PMID:24315724, DOI:10.1016/S01406736(13)62343-0

2. Seiffge DJ, De Marchis GM, Koga M, Paciaroni M, Wilson D, Cappellari M, Macha K, Tsivgoulis G, Ambler G, Arihiro S, Bonati LH, Bonetti B, Kallmünzer B, Muir KW, Bovi P, Gensicke $\mathrm{H}$, Inoue M, Schwab S, Yaghi S, Brown MM, Lyrer P, Takagi M, Acciarrese M, Jager HR, Polymeris AA, Toyoda K, Venti M, Traenka C, Yamagami H, Alberti A, Yoshimura S, Caso V, Engelter ST, Werring DJ, RAF, RAF-DOAC, CROMIS-2, SAMURAI, NOACISP, Erlangen, and Verona registry collaborators: Ischemic stroke despite oral anticoagulant therapy in patients with atrial fibrillation. Ann Neurol 2020; 87: 677-687. DOI:10.1002/ana.25700

3. Tomita H, Hagii J, Metoki N, Saito S, Shiroto H, Hitomi H, Kamada T, Seino S, Takahashi K, Sasaki S, Yasujima M, Okumura $\mathrm{K}$ : Severity and functional outcome of patients with cardioembolic stroke occurring during non-vitamin $\mathrm{K}$ antagonist oral anticoagulant treatment. J Stroke Cerebrovasc Dis 2015; 24: 1430-1437. PMID:25843224, DOI:10.1016/j.jstrokecerebrovasdis.2015.03.004 
4. Xian Y, O'Brien EC, Liang L, Xu H, Schwamm LH, Fonarow GC, Bhatt DL, Smith EE, Olson DM, Maisch L, Hannah D, Lindholm B, Lytle BL, Pencina MJ, Hernandez AF, Peterson ED: Association of preceding antithrombotic treatment with acute ischemic stroke severity and in-hospital outcomes among patients with atrial fibrillation. JAMA 2017; 317: 1057-1067. PMID:28291892, DOI:10.1001/jama.2017.1371

5. Auer E, Frey S, Kaesmacher J, Hakim A, Seiffge DJ, Goeldlin M, Arnold M, Fischer U, Jung S, Meinel TR: Stroke severity in patients with preceding direct oral anticoagulant therapy as compared to vitamin K antagonists. J Neurol 2019; 266: 2263-2272. PMID:31165232, DOI:10.1007/s00415-019-09412-y

6. Meinel TR, Branca M, De Marchis GM, Nedeltchev K, Kahles T, Bonati L, Arnold M, Heldner MR, Jung S, Carrera E, Dirren E, Michel P, Strambo D, Cereda CW, Bianco G, Kägi G, Vehoff J, Katan M, Bolognese M, Backhaus R, Salmen S, Albert S, Medlin F, Berger C, Schelosky L, Renaud S, Niederhauser J, Bonvin C, Schaerer M, Mono ML, Rodic B, Tarnutzer AA, Mordasini P, Gralla J, Kaesmacher J, Engelter S, Fischer U, Seiffge DJ, Investigators of the Swiss Stroke Registry: Prior anticoagulation in patients with ischemic stroke and atrial fibrillation. Ann Neurol 2021; 89: 42-53. DOI:10.1002/ana.25917

7. Macha K, Marsch A, Siedler G, Breuer L, Strasser EF, Engelhorn T, Schwab S, Kallmünzer B: Cerebral ischemia in patients on direct oral anticoagulants. Stroke 2019; 50: 873-879. PMID:30852963, DOI:10.1161/STROKEAHA.118.023877

8. Cockcroft DW, Gault H: Prediction of creatinine clearance from serum creatinine. Nephron 1976; 16: 31-41. PMID:1244564, DOI:10.1159/000180580

9. Brott T, Adams HP, Olinger CP, Marler JR, Barsan WG, Biller J, Spilker J, Holleran R, Eberle R, Hertzberg V: Measurements of acute cerebral infarction: a clinical examination scale. Stroke 1989; 20: 864-870. PMID:2749846, DOI:10.1161/01.STR.20.7.864

10. Gage BF, Waterman AD, Shannon W, Boechler M, Rich MW, Radford MJ: Validation of clinical classification schemes for predicting stroke: results from the National Registry of Atrial Fibrillation. JAMA 2001; 285: 2864-2870. PMID:11401607, DOI:10.1001/jama.285.22.2864

11. Lip GY, Nieuwlaat R, Pisters R, Lane DA, Crijns HJ: Refining clinical risk stratification for predicting stroke and thromboembolism in atrial fibrillation using a novel risk factor-based approach: The Euro Heart Survey on Atrial Fibrillation. Chest 2010; 137: 263-272. PMID:19762550, DOI:10.1378/chest.09-1584

12. Adams HP Jr, Bendixen BH, Kappelle LJ, Biller J, Love BB, Gordon DL, Marsh EE: Classification of subtype of acute ischemic stroke. Definitions for use in a multicenter clinical trial. TOAST. Trial of Org 10172 in Acute Stroke Treatment. Stroke 1993; 24: 35-41. PMID:7678184, DOI:10.1161/01.STR.24.1.35
13. Samuelson BT, Cuker A, Siegal DM, Crowther M, Garcia DA: Laboratory assessment of the anticoagulant activity of direct oral anticoagulants: a systematic review. Chest 2017; 151: 127-138. PMID:27637548, DOI:10.1016/j.chest.2016.08.1462

14. Katsumata M, Oki K, Tsukada N, Abe T, Itoh Y, Takahashi S, Suzuki N: Rivaroxaban promotes reduction of embolus size within cerebrocortical microvessels in a mouse model of embolic stroke. Keio J Med 2019; 68: 45-53. PMID:30504650, DOI:10.2302/ kjm.2018-0010-OA

15. Purrucker JC, Haas K, Rizos T, Khan S, Poli S, Kraft P, Kleinschnitz C, Dziewas R, Binder A, Palm F, Jander S, Soda H, Heuschmann PU, Veltkamp R, Dichgans M, Gröschel K, Eicke M, Ertl M, Hennerici MG, Hobohm C, Höhle T, Jüttler E, Khaw A, Kraft A, Köhrmann M, Meisel F, Neumann-Haefelin T, Opherk C, Röther J, Schmid E, Seidel G, Tanislav C, Thomalla G, Wartenberg K, Weimar C, RASUNOA Investigators (Registry of Acute Stroke Under New Oral Anticoagulants): Coagulation testing in acute ischemic stroke patients taking non-vitamin K antagonist oral anticoagulants. Stroke 2017; 48: 152-158. PMID:27899756, DOI:10.1161/STROKEAHA.116.014963

16. Ebner M, Birschmann I, Peter A, Härtig F, Spencer C, Kuhn J, Blumenstock G, Zuern CS, Ziemann U, Poli S: Emergency coagulation assessment during treatment with direct oral anticoagulants. Stroke 2017; 48: 2457-2463. PMID:28775134, DOI:10.1161/ STROKEAHA.117.017981

17. Seiffge DJ, Kägi G, Michel P, Fischer U, Béjot Y, Wegener S, Zedde M, Turc G, Cordonnier C, Sandor PS, Rodier G, Zini A, Cappellari M, Schädelin S, Polymeris AA, Werring D, Thilemann S, Maestrini I, Berge E, Traenka C, Vehoff J, De Marchis GM, Kapauer M, Peters N, Sirimarco G, Bonati LH, Arnold M, Lyrer PA, De Maistre E, Luft A, Tsakiris DA, Engelter ST, Novel Oral Anticoagulants in Stroke Patients study group: Rivaroxaban plasma levels in acute ischemic stroke and intracerebral hemorrhage. Ann Neurol 2018; 83: 451-459. PMID:29394504, DOI:10.1002/ ana. 25165

18. Seiffge DJ, Polymeris AA, Fladt J, Lyrer PA, Engelter ST, De Marchis GM: Management of patients with stroke treated with direct oral anticoagulants. J Neurol 2018; 265: 3022-3033. PMID:30293111, DOI:10.1007/s00415-018-9061-y

19. Ebner M, Birschmann I, Peter A, Spencer C, Härtig F, Kuhn J, Blumenstock G, Zuern CS, Ziemann U, Poli S: Point-of-care testing for emergency assessment of coagulation in patients treated with direct oral anticoagulants. Crit Care 2017; 21: 32. PMID:28196509, DOI:10.1186/s13054-017-1619-z

20. Ebner M, Peter A, Spencer C, Härtig F, Birschmann I, Kuhn J, Wolf M, Winter N, Russo F, Zuern CS, Blumenstock G, Ziemann U, Poli S: Point-of-care testing of coagulation in patients treated with non-vitamin $\mathrm{K}$ antagonist oral anticoagulants. Stroke 2015; 46: 2741-2747. PMID:26272385, DOI:10.1161/ STROKEAHA.115.010148 